\title{
Undenatured collagen type II for the treatment of osteoarthritis: a review
}

\author{
Ram Prabhoo" ${ }^{1}$ Gauri Billa ${ }^{2 *}$ \\ ${ }^{1}$ Mukund Hospital, J B Nagar, Andheri Kurla Road, Andheri East, Mumbai, Maharashtra, India \\ ${ }^{2}$ Abbott Healthcare Pvt Ltd, Mumbai, Maharashtra, India
}

Received: 10 July 2018

Accepted: 27 July 2018

*Correspondence:

Dr. Gauri Billa,

E-mail: gauri.billa@abbott.com

Copyright: (c) the author(s), publisher and licensee Medip Academy. This is an open-access article distributed under the terms of the Creative Commons Attribution Non-Commercial License, which permits unrestricted non-commercial use, distribution, and reproduction in any medium, provided the original work is properly cited.

\begin{abstract}
Osteoarthritis is a prevalent musculoskeletal condition worldwide with rising rates in elderly people. Both mechanical and immunological factors are implicated in the pathogenesis of osteoarthritis resulting in destruction of the articular cartilage. Non-steroidal anti-inflammatory drugs (NSAIDs) commonly used for the treatment of osteoarthritis, are associated with several adverse events and also do not affect the underlying disease process. Clinicians and patients both seek options which are safe and effective in the treatment of osteoarthritis. Collagen derivatives represent a suitable option in such cases. Collagen is the most abundant component of the cartilage. Collage derivatives have shown to have disease modifying action in osteoarthritis. Depending on the degree of hydrolysis and molecular weight, collage derivatives are classified into undenaured collagen, gelatin and collage hydrolysate. Collagen derivatives are well tolerated without major safety concerns. Undenatured type II collagen has shown to provide significant improvement in patients with osteoarthritis. In this article we discuss, the pathophysiology of osteoarthritis with focus on immunological factors and evidence for the use of undenatured collagen type II in osteoarthritis.
\end{abstract}

Keywords: Efficacy, Osteoarthritis, Undenatured collagen type II

\section{INTRODUCTION}

Osteoarthritis is one of the most prevalent chronic musculoskeletal conditions worldwide. It is a common cause of pain and disability among many patients. ${ }^{1}$ Other symptoms of osteoarthritis include stiffness and reduced movements. Overall the disease results in impaired quality of life. ${ }^{2}$ Coupled with high prevalence and associated morbidity, the disease seeks attention at personal as well as national and even global level. It is estimated that osteoarthritis affects up to $15 \%$ people worldwide. The disease is more common in elderly with estimation of affecting more than $50 \%$ people after 60 years of their life. ${ }^{3}$ According to a community based cross sectional study, overall prevalence of knee osteoarthritis in India is $28.7 \%$. The prevalence of disease rises with increase in age. Although the disease is observed and common in both genders, females are affected more commonly than men. The other risk factors for the development of knee osteoarthritis include obesity and sedentary lifestyle. ${ }^{1}$

\section{Structure and composition of articular cartilage}

Articular cartilage is composed of cellular and an extracellular compartment. ${ }^{4}$ The cells of articular cartilage i.e. chondrocytes constitute less than five percent of the cartilage volume. Extracellualr matrix constitutes the other part of the articular cartilage. ${ }^{3}$ The extracellular compartment of articular cartilage consists of collagen, proteoglycans, and noncollagenous matrix proteins with first two being the primary components. ${ }^{4,5}$ 
As such collagen is abundantly present in the human body, accounting to about one third of the total proteins. $^{6,9}$ It represents the most common part of the extracellular matrix. ${ }^{6}$ Collagen is the structural backbone of the extracellular matrix which provides protection against tensile forces and help in maintenance of the structural integrity. ${ }^{3,4}$ Collagen and fibronectin interaction helps to maintain the extracellular matrix structure and cellular functions. ${ }^{8}$

Out of several types of collagens identified, type II is the major component of cartilage whereas tendons are mainly composed of type I collagen. ${ }^{4,5}$ During development, the major collagens in the articular cartilage are type II, IX and XI. In the cartilage matrix of fetus and adult, type II collagen represent $75 \%$ and more than $90 \%$ of the total collagen respectively. Cross-linking of collagen IX interacts with type II collagen and other collagen IX molecules. ${ }^{10}$

Other fibrous tissues consists of collagen fibrils formed largely from type I collagen. Collagen fibrils formed mainly from type I collagen differ slightly in their structure from those formed mainly from type II collagen. ${ }^{6}$ Another important component of the articular cartilage is the proteoglycan aggrecan which are present between the collagen fibrils. ${ }^{3}$ The complex structure of collagen is resistant to proteolytic enzymes except specific matrix metalloproteinases.

\section{Pathophysiology of osteoarthritis}

Osteoarthritis occurs because of imbalance of cartilage synthesis versus cartilage breakdown. The disease is associated with cartilage damage and synovial inflammation. Several complex biochemical mechanisms are involved in the pathogenesis of disease. ${ }^{11}$ Progressive degeneration of articular cartilage is the characteristic of osteoarthritis. $^{3}$ Breakdown of the cartilage with proteolytic enzymes is one of the principal mechanisms in its pathogenesis with metalloproteinases (MMPs) being the important proteolytic enzymes involved in the breakdown of cartilage. ${ }^{11}$ Several types of MMPs cleaving different types of collagen types are known. Collagen II is preferentially cleaved by MMP-13. ${ }^{9}$

Cytokines (e.g. IL-1,TNF-alpha) up-regulate MMP gene expression and also dampen the compensatory mechanisms required for integrity of the extracellular matrix (ECM). ${ }^{11}$ Agents with potential of neutralization of IL-1 and/or TNF-alpha up-regulation of MMP gene expression may be useful therapeutic options for the treatment of osteoarthritis. $^{11}$

\section{Inflammatory and immunological mechanism in osteoarthritis}

Endogenous substances in the articular cartilage may serve as antigenic stimulus and immune reactivity to such antigens may be involved in the process of inflammatory arthritis. Fibronectin fragments may play an immunogenicity role by stimulating the formation of cytokines and other enzymes from chondrocytes contributing to the cartilage damage in osteoarthritis. ${ }^{5}$ Presence of anti-type II collagen antibodies in osteoarthritic cartilage also suggests the role of immunological mechanism in the development of osteoarthritis. $^{12}$

Clinical features such as swelling and synovial effusion, changes in synovial membrane and presence of biomarkers in the synovial fluid suggest the role of inflammatory process in the pathogenesis of osteoarthritis. In osteoarthritis, role of cellular as well as humoral immunity to cartilage and chronic inflammation because of release of auto-antigens and autoimmune reactions in causing destruction of cartilage is suggested. Thus both mechanical and immunological pathway seems to play a role in the pathogenesis of osteoarthritis (Figure 1).

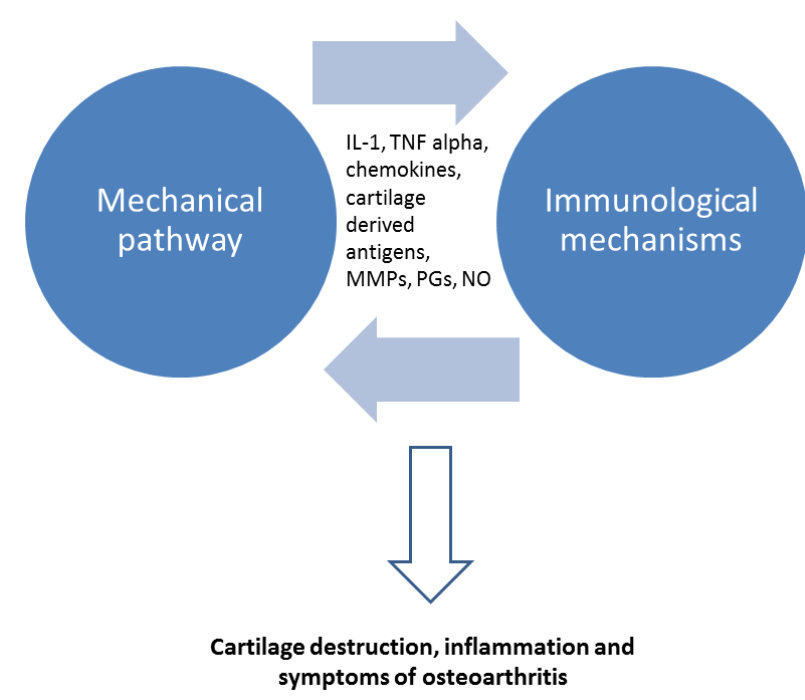

Figure 1: Pathogenesis of osteoarthritis.

IL-1-interleukin-1; TNFalpha-tumor necrosis factor alpha; MMPs: matrix metalloproteinases; NO: nitric oxide; PGs: prostaglandins.

Because of their ability to provide selective and long term inhibition of inflammation, Treg cells are attractive target for the reducing inflammation in an antigen specific manner. ${ }^{13}$

\section{Treatment of osteoarthritis}

Treatment of osteoarthritis can be broadly classified as non-pharmacological and pharmacological management. Exercise and weight reduction (for overweight and obese people) are the non-pharmacological measures whereas analgesics such as paracetamol or non-steroidal antiinflammatory drugs (NSAIDs) are commonly prescribed pharmacological agents. Paracetamol and NSAIDs provide only symptomatic relief, but do not have disease modifying effect. Moreover, these drugs are associated 
with several adverse effects. ${ }^{2}$ Because of these limitations, alternative options which have no major adverse events and also prevent damage to the joint structures are often sought by the clinicians as well as by patients.

\section{Different types of collagen derivatives}

Collagen derivatives are attractive options for the management of osteoarthritis. They have disease modifying action in osteoarthritis. Based on the degree of hydrolysis and their molecular weight, collagen derivatives are classified into undenaured collagen, gelatin and collage hydrolysate. Between these three groups, undenatured collagen has highest molecular weight i.e. $300 \mathrm{kDa}$ whereas molecular weight of collagen hydrolysate is lowest ranging between 2 to 9 $\mathrm{kDa}$. A systematic review of literature suggests that collagen derivatives are well tolerated without major safety concerns. ${ }^{2}$

Presence of intact epitopes on undenatured collagen helps in oral tolerization, differentiating its mechanism of action from the hydrolysed collagen.

Undenatured type II collagen is a nutritional supplement and products containing glycosylated, undenatured typeII collagen are available for the management of osteoarthritis. $^{14-16}$

\section{Mechanism of action of undenatured collagen type II}

Humans are exposed to antigens through several routes. The gut-associated lymphoid tissue (GALT) is the major organ for the exposure of antigens. ${ }^{17}$ Oral tolerance i.e. the ability of mucosal immune system to actively inhibit systemic immune responses to fed antigens has been used as a therapy for some chronic inflammatory and autoimmune conditions. ${ }^{18}$

Autoimmunity is the result of an impaired balance of pathogenic mechanism versus protective response of the body. The manifestations of autoimmunity may be systemic or limited to specific organ. ${ }^{19}$ Mucosal tolerance helps to prevent pathogenic reactivity to antigens entering the body through mucosa. "Oral tolerance" is involved in the mechanism of action of undenatured collagen type II. Oral tolerance is the response given by the gutassociated lymphoid tissue (GALT) to the harmless gut antigens. Exposure of such antigens induces local and systemic immunological tolerance. ${ }^{21}$

After oral administration, epitopes of undenatured collagen type II interacts with GALT in the duodenum and induce oral tolerance to antigens and reduce systemic $\mathrm{T}$ cell attack on the cartilage. Small oral doses of glycosylated undenatured collagen type II presents active epitopes with correct three dimensional structures to the GALT. This helps to develop the immune tolerance. Small doses of undenatured collagen type II prevent the attack by killer T cells. ${ }^{16}$ In osteoarthritis, immune related component is not involved in the pathogenesis, but has similarities with rheumatoid arthritis in the form of cartilage damage and inflammatory response. ${ }^{21}$

Receptor activator of nuclear factor kappaB ligand (RANKL) is an osteoclastogenic mediator. In mice with collagen arthritis, oral type II collagen has shown to suppress IL-17 associated RANKL expression of CD4+ T cells. $^{22}$

\section{Evidence for undenatured collagen type II}

Undenatured collagen type II has been studied in both animal and clinical studies. In the following section evidence for undenatured type II collagen in pre-clinical and clinical trials is discussed.

\section{Pre-clinical evidence for undenatured collagen type II}

A study in the rat model of osteoarthritis reported several benefits after treatment with undenatured collagen-II including preservation of weight bearing capacity of the injured leg and integreity of cancellous bone suggesting potential for prevention of worsening of articular cartilage damage. ${ }^{23}$

In another study, effect of porcine native type II collagen was studied in the rat model of osteoarthritis. Porcine native type II collagen was given orally for 13 days. Effect was tested by Paw pressure test and Electronic Von Frey test stimuli. Articular pain in the damaged joint and plasma and urine levels of a biomarker of cartilage destruction, cross linked C-Telopeptide of Type II Collagen (CTX-II) were measured. After two weeks, porcine native type II collagen showed a significant prevention of pain threshold alterations induced by sodium monoiodoacetate (MIA). Reduction in pain was higher with lowering of dose. There was also reduction in plasma and urine levels of CTX-II. Low dosages of native type II collagen showed pain reduction and indicated protective effect on the cartilage. ${ }^{21}$

\section{Evidence from clinical trials}

Undenatured collagen type II has been evaluated for its effect in healthy volunteers experiencing knee pain after physical activity and also for its efficacy and safety in the treatment of osteoarthritis. The results of these studies are briefly summarized here.

\section{Efficacy and safety of undenatured collagen type II in healthy volunteers experiencing pain after physical activity}

A randomized, double blind, placebo controlled study was conducted among healthy subjects having knee pain with physically activity to understand the efficacy and tolerability of undenatured collagen type II in moderating joint function and joint pain $(n=55) .{ }^{14}$ Undenatured 
collagen type II $40 \mathrm{mg}$ daily was given to 27 healthy subjects for four months. The other 28 subjects received placebo. The efficacy was determined by measuring joint function in terms of degree of knee flexion and knee extension. Time to pain and time for recovering from joint pain after exercise was also noted. Subjects receiving supplementation of undenatured collagen type II showed significant improvement in knee extension as compared with placebo $\left(81.0 \pm 1.3^{\circ}\right.$ vs. $74.0 \pm 2.2^{\circ}$; $\mathrm{p}=0.011$ ). Similarly, there was also significant improvement in knee extension as compared with baseline $\left(81.0 \pm 1.3^{\circ}\right.$ vs. $\left.73.2 \pm 1.9^{\circ} ; \mathrm{p}=0.002\right)$. After three months of supplementation also, there was significant change in average knee extension in subjects receiving undenatured type II collagen $(p=0.045)$ as compared to baseline status. Placebo group did not show significant change at any time. Time required for initial joint discomfort increased significantly after four months of undenatured collagen type II supplementation $(2.8 \pm 0.5$ vs. $1.4 \pm 0.2 \mathrm{~min}, \mathrm{p}=0.019)$ as compared with baseline. In the placebo group, there was no significant effect. The supplementation was well tolerated without product related adverse events. ${ }^{14}$ The results of this study indicate potential for use of undenatured type II collagen in knee osteoarthritis.

\section{Efficacy and safety of undenatured collagen type II in patients with osteoarthritis}

Crowley and colleagues compared efficacy and safety of undenatured collagen type II with the combination of glucosamine and chondroitin in the treatment of knee osteoarthritis. ${ }^{24}$ In this study, a total of 52 patients were enrolled of which 26 received undenatured collagen type II. Overall results of this study showed undenatured collagen type II given for three months is more efficacious as compared to combination of glucosamine plus chondroitin.

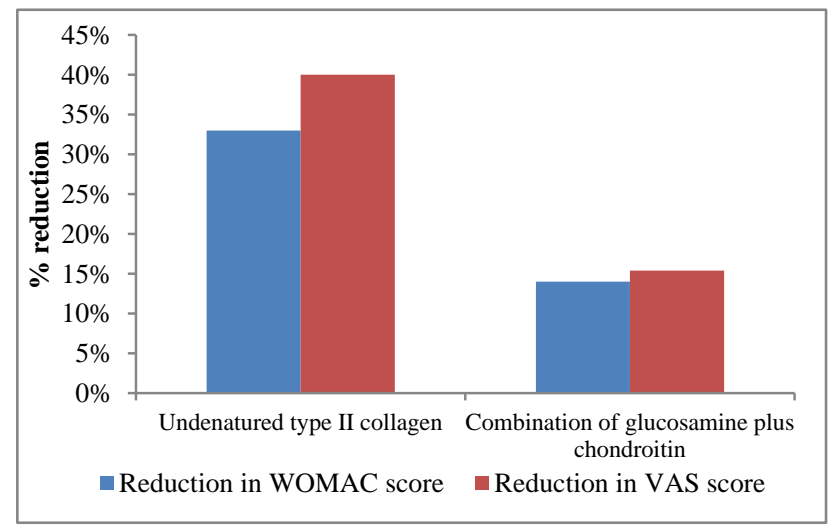

\section{Figure 2: Comparative reduction in the WOMAC score and VAS score after three months in undenatured type II collagen versus combination of glucosamine plus chondroitin.}

In the group of patients who received undenatured collagen type II, WOMAC score was reduced by $33 \%$ as compared to $14 \%$ in the comparator group. Treatment with undenatured collagen type II showed significant improvement in WOMAC scores at one month, two months and three months (all three time points $\mathrm{p}<0.005$ ) whereas combination of glucosamine plus chondroitin showed significant improvement only at one month $(p<0.005)$ and two months $(p<0.5)$. Similarly, the VAS score was reduced by $40 \%$ in the undenatured collagen type II compared to $15.4 \%$ in the other group (Figure 2). Treatment with undenatured collagen type II showed significant reduction at two and three months $(\mathrm{p}<0.05$ at both time points). Combination of glucosamine plus chondroitin showed significant improvement only at one month $(\mathrm{p}<0.05)$.

The Lequesne's functional index (pain during daily activities) score was reduced by $20 \%$ in the undenatured collagen type II versus $6 \%$ in the other group. Undenatured collagen type II showed significant improvement in daily activities indicating improvement of quality of life. There was no significant difference in the adverse events between two groups. ${ }^{24}$

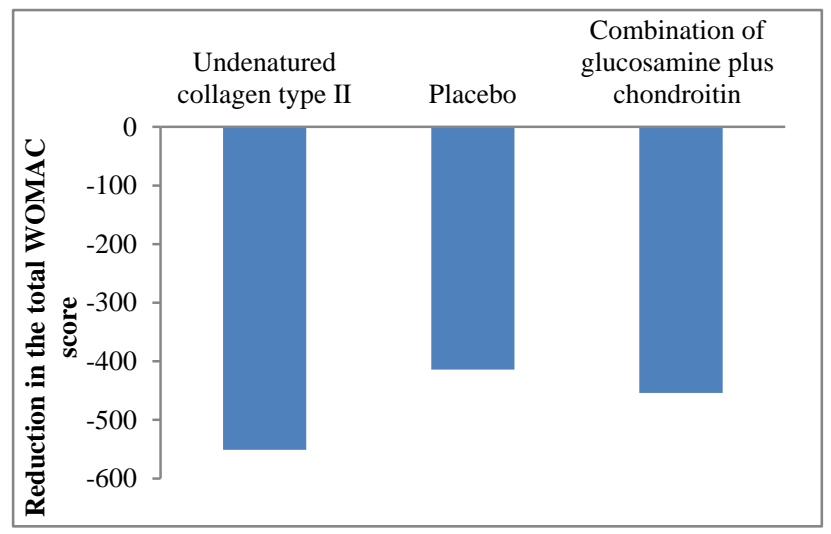

Figure 3: Comparative reduction in the total WOMAC score at six month in undenatured type II collagen versus combination of glucosamine plus chondroitin and placebo.

Another multicentre, randomized, double blind study ${ }^{15}$ compared efficacy and tolerability of undenatured collagen type II (40 mg daily) versus placebo and glucosamine hydrochloride $(1500 \mathrm{mg})$ plus chondroitin sulphate (1200 mg) (GC) for six months in patients knee osteoarthritis $(n=191)$. The change in total Western Ontario McMaster Universities Osteoarthritis Index (WOMAC) was the primary end point of this study. The change in the total WOMAC score was statistically significant with the undenatured collagen type II as compared with other two groups (placebo -551 vs. -414; $95 \%-232$ to $-42 ; \mathrm{p}=0.002$; combination of glucosamine plus chondroitin -551 vs. $-45495 \%$ CI -190 to -3 ; $\mathrm{p}=0.04$; Figure 3). There was significant decrease in all three (pain, stiffness and physical function) WOMAC subscales with undenatured collagen type II as compared with placebo and for WOMAC pain and stiffness subscale as compared with combination of glucosamine 
plus chondroitin. Analysis of the reduction in the mean VAS score at the end of study showed significant reduction with undenatured collagen versus both the groups (placebo $\mathrm{p}=0.002$ and combination of glucosamine plus chondroitin $\mathrm{p}=0.025)$. However, combination of glucosamine plus chondroitin did not show significant difference as compared with placebo.
The investigators also measured change in cartilage oligomeric matrix protein (COMP). There was greater reduction in the total WOMAC score among patients receiving undenatured collagen type II who had baseline COMP level at least $285 \mathrm{ng} / \mathrm{ml}$ as compared to other two groups. Therapy was well tolerated without significant safety concerns. ${ }^{15}$

Table 1: Summary of clinical evidence for undenatured collagen type II in the management of osteoarthritis and healthy subjects with exercise induced pain.

\begin{tabular}{|c|c|c|c|c|}
\hline Authors (year) & Study design & Subjects & $\mathbf{N}$ & Outcome \\
\hline Crowley et al ${ }^{24}$ & $\begin{array}{l}\text { Comparative study versus } \\
\text { combination of glucosamine } \\
\text { and chondroitin }\end{array}$ & $\begin{array}{l}\text { Knee } \\
\text { osteoarthritis. }\end{array}$ & 52 & $\begin{array}{l}\text { Better efficacy as compared with } \\
\text { combination of glucosamine plus } \\
\text { chondroitin }\end{array}$ \\
\hline Lugo et al $^{14}$ & $\begin{array}{l}\text { Randomized, double blind, } \\
\text { placebo controlled study }\end{array}$ & $\begin{array}{l}\text { Healthy subjects } \\
\text { having knee pain } \\
\text { with physically } \\
\text { activity }\end{array}$ & 55 & $\begin{array}{l}\text { Significant improvement in knee } \\
\text { extension; after three months also, } \\
\text { there was significant change in } \\
\text { average knee extension compared to } \\
\text { baseline status. }\end{array}$ \\
\hline Lugo et al $^{15}$ & $\begin{array}{l}\text { Multicentre, randomized, } \\
\text { double blind study versus } \\
\text { placebo and combination of } \\
\text { glucosamine hydrochloride } \\
\text { plus chondroitin sulphate }\end{array}$ & $\begin{array}{l}\text { Patients knee } \\
\text { osteoarthritis }\end{array}$ & 191 & $\begin{array}{l}\text { Significant change in the total } \\
\text { WOMAC score versus two groups; } \\
\text { significant decrease in WOMAC } \\
\text { subscales (pain, stiffness and } \\
\text { physical function) versus placebo } \\
\text { and WOMAC pain and stiffness } \\
\text { subscale versus combination of } \\
\text { glucosamine plus chondroitin; } \\
\text { significant reduction in the mean } \\
\text { VAS score versus both groups }\end{array}$ \\
\hline
\end{tabular}

Table 1 summarizes the clinical evidence for undenatured collagen type II in human subjects (healthy subjects with pain after exercise and patients with osteoarthritis).

\section{Availability and place of undenatured collagen type II in the management of osteoarthritis}

Undenatured collagen type II is available as $40 \mathrm{mg}$ capsules containing $10 \mathrm{mg}$ of undenatured collagen Type II. The suggested dosage of undenatured collagen type II is one capsule to be taken once a day. Undenatured collagen type II represents an effective and safe armamentarium for patients with osteoarthritis targeting the underlying disease process as well as providing symptomatic relief.

\section{CONCLUSION}

Osteoarthritis is a significant medical concern across the world including in Indian population. Significant progress has been made in terms of understanding of the disease process and possible interventions to reduce the risk of osteoarthritis related burden. Although several options are available for the management of osteoarthritis, many are associated with major limitations. Undenatured type II collagen is a nutritional supplement that has been evaluated for its efficacy and safety in healthy subjects experiencing pain after exercise and patients with knee osteoarthritis. Based on the available evidence it is clear that undenatured type II collagen is effective in improving joint discomfort associated with osteoarthritis. Undenatured type II collagen supplement has a significant potential for use in patients with osteoarthritis because of its safety profile without any significant concerns.

\section{ACKNOWLEDGEMENTS}

We thank Dr. Anand Patil for writing support.

Funding: No funding sources

Conflict of interest: Dr Billa authored this publication in the capacity as an employee of Abbott Healthcare Pvt Ltd. Dr Prabhoo have co-authorized this publication. The authors have declared and confirmed that there is no conflict of interest with respect to this authored publication.

Ethical approval: Not required

\section{REFERENCES}

1. Pal CP, Singh P, Chaturvedi S, Pruthi KK, Vij A. Epidemiology of knee osteoarthritis in India and related factors. Indian J Orthop. 2016;50:518-22.

2. Van Vijven JPJ, Luijsterburg PAJ, Verhagen AP, van Osch GJVM, Kloppenburg M, Bierma-Zeinstra SMA. Symptomatic and chondroprotective 
treatment with collagen derivatives in osteoarthritis: a systematic review. Osteoarthritis Cartilage. 2012;20:809-21.

3. Poole AR, Kobayashi M, Yasuda T, Laverty S, Mwale F, Kojima T, et al. Type II collagen degradation and its regulation in articular cartilage in osteoarthritis. Ann Rheum Dis 2002;61(2):78-81.

4. Diab M. The role of type IX collagen in osteoarthritis and rheumatoid arthritis. Orthop Rev. 1993;22:165-70.

5. Yuan Q-H, Masuko-Hongo K, Kato T, Nishioka K. Immunologic intervention in the pathogenesis of osteoarthritis. Arthritis Rheumatism. 2003;48:60211.

6. Shoulders MD, Raines RT. Collagen structure and stability. Annu Rev Biochem. 2009;78:929-58.

7. Franchi M, Trire A, Quatanta M, Orsini E, Ottani V. Collagen structure of tendon relates to function. The Scientific World J. 2007;7:404-20.

8. An B, Abbonante V, Yigit S, Balduini A, Kaplan DL, Brodsky DL. Definition of the native and denatured type II collagen binding site for fibronectin using a recombinant collagen system. The J Biological Chem. 2014;289:4941-51.

9. Ricard-Blum S. The collagen family. Cold Spring Harb Perspect Biol. 2011;3:a004978.

10. Eyre DR, Weis MA, Wu J-J. Articular cartilage collagen: An irreplaceable framework? European Cells and Materials. 2006;12:57-63.

11. Fernandes JC, Martel-Pelletier J, Pelletier JP. The role of cytokines in osteoarthritis pathophysiology. Biorheology. 2002;39:237-46.

12. Jasin HE. Autoantibody specificities of immune complexes sequestered in articular cartilage of patients with rheumatoid arthritis and osteoarthritis. Arthritis Rheum. 1985;28:241-8.

13. Asnagli H, Martire D, Belmonte N, Quentin J, Bastian H, Boucard-Jourdin M. Type 1 regulatory T cells specific for collagen type II as an efficient cellbased therapy in arthritis. Arthritis Res Therapy. 2014;16:115.

14. Lugo JP, Saiyed ZM, Lau FC, Molina JPL, Pakdaman MN, Shamie AN. Undenatured type II collagen (UC-IIß) for joint support: a randomized, double-blind, placebo-controlled study in healthy volunteers. J Int Society Sports Nutr. 2013;10:48.

15. Lugo JP, Saiyed ZM, Lane NE. Efficacy and tolerability of an undenatured type II collagen supplement in modulating knee osteoarthritis symptoms: a multicenter randomized, double-blind, placebo-controlled study. Nutrition J. 2016;15:14.

16. Bagchi D, Misner B, Bagchi M, Kothari SC, Downs BW, Fafard RD, et al. Effects of orally administered undenatured type II collagen against arthritic inflammatory diseases: A mechanistic exploration. Int J Clin Pharm Res. 2002;22:101-10.

17. Weiner HL, da Cunha AP, Quintana F, Wu H. Oral tolerance. Immunol Rev. 2011;241:241-59.

18. Kraus TA, Mayer L. Oral tolerance and inflammatory bowel disease. Curr Opin Gastroenterol. 2005;21(6):692-6.

19. Astry B, Venkatesha SH, Moudgil KD. Temporal cytokine expression and the target organ attributes unravel novel aspects of autoimmune arthritis. Indian J Med Res. 2013;138:717-31.

20. Broere F, Wieten L, Koerkamp EIK, van Roon JAG, Guichelaar T, Lafeber FPJG. Oral or nasal antigen induces regulatory $\mathrm{T}$ cells that suppress arthritis and proliferation of arthritogenic $\mathrm{T}$ cells in joint draining lymph nodes. The J Immunol. 2008;181:899-906.

21. Di Cesare Mannelli L, Micheli L, Zanardelli M, Ghelardini C. Low dose native type II collagen prevents pain in a rat osteoarthritis model. BMC Musculoskeletal Disorders. 2013;14:228.

22. Ju JH, Cho ML, Jhun JY, Park MJ, Oh HJ, Min SY, et al. Oral administration of type-II collagen suppresses IL-17-associated RANKL expression of CD4+ T cells in collagen-induced arthritis. Immunol Lett. 2008;117:16-25.

23. Bagi CM, Berryman ER, Teo S, Lane NE. Oral administration of undenatured native chicken type II collagen (UC-II) diminished deterioration of articular cartilage in a rat model of osteoarthritis (OA). Osteoarthritis and Cartilage. 2017;25:208090.

24. Crowley DC, Lau FC, Sharma P, Evans M, Guthrie N, Bagchi M. Safety and efficacy of undenatured type II collagen in the treatment of osteoarthritis of the knee: a clinical trial. Int J Med Sci. 2009;6:31221.

Cite this article as: Prabhoo R, Billa G. Undenatured collagen type II for the treatment of osteoarthritis: a review. Int J Res Orthop 2018;4:684-9. 